(с) Н.Б. Чабанова ${ }^{1 *}$, Т.Н. Василькова', В.А. Полякова', С.И. Матаев ${ }^{2}$

'ФГБОУ ВО «Тюменский государственный медицинский университет» Минздрава России, Тюмень, Россия

²ОО «Многопрофильный медицинский центр "Лимфомед"», Тюмень, Россия

Обоснование. Ожирение в настоящее время является одной из наиболее значимых проблем здравоохранения во всем мире. Свойственное ожирению избыточное накопление жировой ткани сопровождается метаболическими нарушениями, в том числе повышенной секрецией лептина, способствующими, в свою очередь, увеличению риска гестационных осложнений.

Цель. Оценить уровень лептина в сыворотке крови беременных в зависимости от массы тела, массы и характера распределения жировой ткани в различные сроки гестации.

Методы. Объектом исследования явились 211 женщин с одноплодной беременностью, наступившей в естественном цикле и завершившейся срочными родами. Всем женщинам проводились антропометрическое исследование, оценка массы жировой ткани методом биоимпедансометрии, характера жироотложения с помощью УзИ жировой ткани, определение уровня сывороточного лептина в сроке 10-14, 24-28 и 36-38 нед беременности.

Результаты. Установлено, что уровень сывороточного лептина нарастает пропорционально предгестационному индексу массы тела у всех беременных начиная с I триместра. Женщины с избыточной массой тела и ожирением на протяжении всего гестационного периода имели достоверно более высокие концентрации лептина, чем при нормальной массе тела ( $<<0,001)$. С увеличением срока беременности мы наблюдали рост уровня сывороточного лептина во всех группах независимо от характера жироотложения. К концу III триместра женщины с нормальной массой тела имели наибольшую величину абсолютной и относительной прибавки массы тела и жировой массы, что сопровождалось увеличением концентрации лептина более чем в 3 раза по отношению к предгестационному уровню.

Заключение. Таким образом, более высокое содержание лептина в сыворотке крови беременных с избыточной массой тела и ожирением в I триместре объясняется избыточным накоплением жировой ткани. Наибольшая величина гестационной прибавки массы тела и жировой массы в группе женщин с нормальным исходным весом сопровождается значительным увеличением уровня лептина на единицу массы тела и жировой массы. Эти данные свидетельствуют, что контроль и ограничение чрезмерной прибавки веса в период беременности может являться мерой профилактики избыточной секреции лептина и связанных с этим гестационных осложнений.

КЛЮЧЕВЫЕ СЛОВА: беременность, ожирение, лептин, жировая ткань, подкожный жир, висцеральный жир.

\title{
INFLUENCE OF MASS AND DISTRIBUTION OF ADIPOSE TISSUE ON THE CONTENT OF LEPTIN IN PREGNANT WOMEN AT DIFFERENT PERIODS GESTATIONS
}

(c) Natalya B. Chabanova1* , Tatyana N. Vasilkova', Valentina A. Polyakova', Sergei I. Mataev²

${ }^{1}$ Tyumen State Medical University, Tyumen, Russia

${ }^{2}$ Multiprofile medical center "Limfomed", Tyumen, Russia

Background: Currently, obesity is one of the most global problem in the world. Redundant accumulation of adipose tissue accompanied by metabolic disorders including high secretion of leptin may lead to an increased risk of gestational complications.

Aims: To assess the level of leptin in pregnant women's blood serum depending on their body weight and the character of content of adipose tissue in different terms of gestation.

Materials and methods: We investigated 211 women with single pregnancies, which came in natural cycles and finished with urgent parturitions. All of them got anthropometric study, assessment of adipose tissue's weight by bioimpedanceometry, character of fat deposition by ultrasound investigation of adipose tissue, determination of the level of whey leptin at 10-14, 24-28, 36-38 weeks of pregnancy.

Results: Established, that the level of leptin increases in proportion to pregestational body mass index from the first trimester. Women with excess body mass and with obesity had higher concentrations of leptin all over gestation, than women with normal body mass $(p<0.001)$. The higher term of pregnancy was, the higher the level of whey leptin was in all groups, independently of character of fat deposition. In the end of third trimester, women with normal body mass had the largest value of absolute and relative increase of body mass and fatty mass, what accompanied by enlargement of the concentration of leptin more than in 3 times for the pregestational level.

Conclusions: In this way, high content of leptin in pregnant women's (with excess body mass and obesity) blood serum in the first trimester is explained by redundant accumulation of the adipose tissue. The largest value of gestational increase 
of body mass and fat mass in group where women had normal initial weight is accompanied by the great increase of the level of leptin on the body weight unit and fat mass. These data indicate, that control and limitation of excessive weight gain while pregnancy can be a measure of prevention of the redundant leptin's secretion and different gestational complications related with it.

KEYWORDS: pregnancy, obesity, leptin, adipose tissue, subcutaneous fat, visceral fat.

\section{ОБОСНОВАНИЕ}

Лептин (от греч. «leptos» - «тонкий») - пептидный гормон, относящийся к адипоцитокинам, регулирующий энергетический обмен. Концентрация лептина в сыворотке крови, какправило, коррелирует смассойжировой ткани и индексом массы тела (ИМТ). Вместе с тем экспериментальные и клинические исследования последних лет дают основания рассматривать лептин не только как гормон, регулирующий аппетит и массу тела, но и участвующий в обеспечении сосудистого, костного и хрящевого роста, функции иммунной системы и системного воспалительного ответа, а также способствующий нормальной физиологии репродуктивной системы, регулируя выработку гонадотропинов [1-4].

Течение физиологической беременности уже с ранних сроков сопровождается значительным увеличением концентрации лептина [5]. Дополнительным источником лептина в гестационном периоде, помимо жировой ткани, являются плацента, плодные оболочки и ткани матки. Во время беременности лептин играет особенно важную роль, участвуя в регуляции материнского энергетического обмена, формировании бластоцисты, снижении сократительной активности гладкой мускулатуры матки, способствуя имплантации, плацентации и нормальному функционированию фетоплацентарного комплекса [6].

При наличии у беременной избыточной массы тела и ожирения метаболические нарушения, характеризующиеся дисфункцией жировой ткани, сопровождаются повышенными концентрациями лептина, создавая предпосылки для возникновения гестационных осложнений [7, 8]. Исследования последних лет демонстрируют связь между повышенной концентрацией лептина В I триместре и риском развития преэклампсии [9], гестационного диабета [10, 11], невынашивания [12-14], макросомии [15] и недостаточного роста плода [16, 17].

Кроме того, существуют различные типы ожирения с преимущественным накоплением жировой ткани в вис- церальной или подкожной области. При этом известно, что наибольшие риски для здоровья представляет именно висцеральная жировая ткань.

Учитывая вышеизложенное, значительный интерес представляет изучение особенностей секреции лептина у беременных с нормальной, избыточной массой тела и ожирением в динамике гестационного процесса.

\section{ЦЕЛЬ}

Оценить уровень лептина в сыворотке крови беременных в зависимости от массы тела, массы и характера распределения жировой ткани в различные сроки гестации.

\section{МЕТОДЫ}

Дизайн исследования

См. рисунок 1.

\section{Критерии соответствия}

В исследовании приняли участие 211 беременных на основании информированного добровольного согласия. Критерии включения в исследование: одноплодная беременность, наступившая в естественном цикле и завершившаяся срочными родами, отсутствие тяжелой экстрагенитальной патологии (артериальная гипертензия, сахарный диабет, системные ревматические заболевания, ВИЧ-инфекция, гепатит В и С, острые или обострение хронических инфекций, онкологическая патология).

Условия проведения

Обследование беременных проводилось на базе ООО «Многопрофильная клиника "Лимфомед"» (г. Тюмень).

Продолжительность исследования

Период проведения исследования составил 1,5 года (июнь 2016 - декабрь 2017 гг.). Обследование было

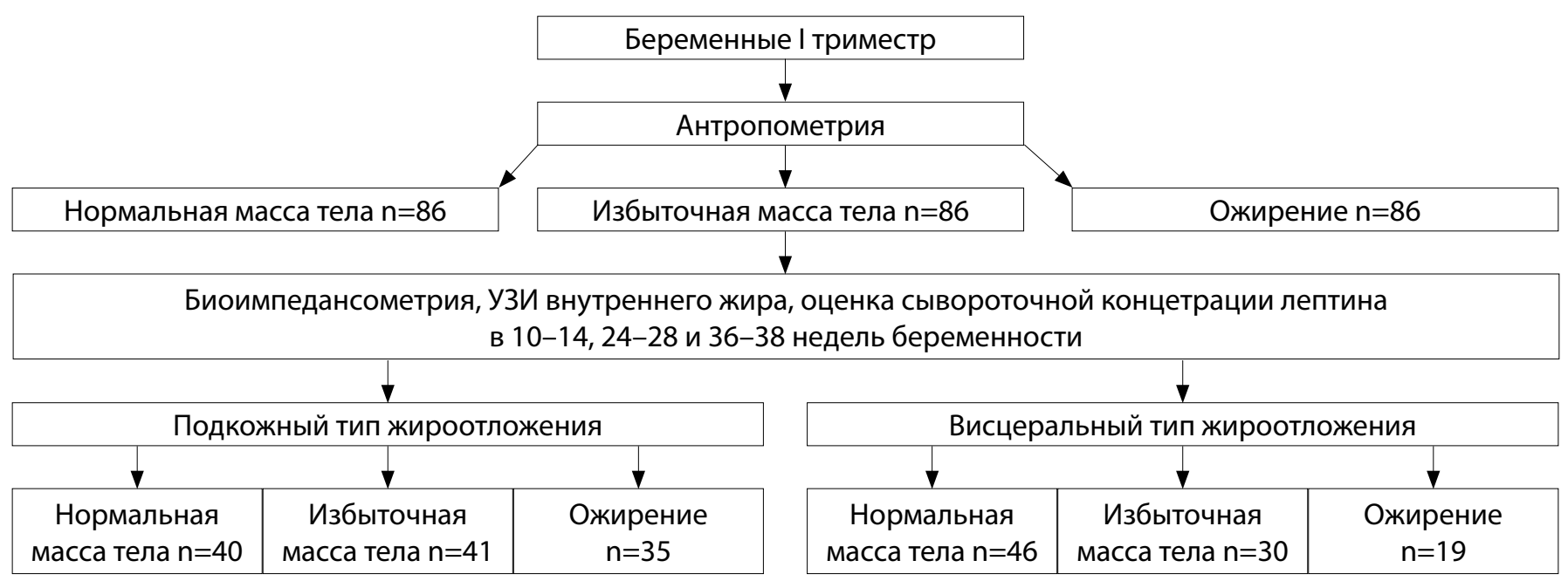

Рис. 1. Дизайн исследования. 
лонгитюдным, с проведением необходимых исследований трижды в течение беременности - в 10-14, 24-28 и 36-38 нед.

\section{Описание медицинского вмешательства}

В соответствии с поставленной целью всем женщинам проводили традиционное антропометрическое обследование, включающее измерение массы тела (в кг), роста (в см), окружности талии (ОТ), объема бедер (ОБ), с последующим вычислением ИМТ - отношения веса (в кг) к росту (в м2) и соотношения ОТ/ОБ.

Массу жировой ткани определяли методом биоимпедансометрии с помощью аппарата АВС-01 «МЕДАСС» («МЕДАСС», Россия) [18].

Характер жироотложения оценивали с помощью УЗИ жировой ткани, используя конвексный датчик с частотой 2-5 МГц, который устанавливался в эпигастральной области, непосредственно под мечевидным отростком, проводилось продольное сканирование вдоль средней линии тела. Определялась толщина слоя внутрибрюшного жира (ВБЖ), измеряемая как расстояние между передней стенкой брюшной аорты и задней поверхностью прямой мышцы живота. Толщина подкожного жира (ПКЖ) определялась как расстояние между передней поверхностью белой линии живота и границей между жиром и кожей, а толщина преперитонеального жира (ППЖ) - как расстояние между задней поверхностью белой линии живота и передней поверхностью печени. Рассчитывали индекс жира брюшной стенки (ИЖБС), который представляет собой отношение максимальной толщины ППЖ к минимальной толщине ПКЖ [19-21]. Висцеральный тип преимущественного накопления жировой ткани устанавливали при величине индекса более 1 и подкожный тип - при показателе индекса менее 1.

Концентрацию лептина в исследуемых сыворотках крови определяли методом иммуноферментного анализа (ИФА) (ELISA, Германия). Регистрация результатов проводилась на горизонтальном фотометре ELx800 (США) при длине волны 450 нм. Нормативными считались показатели лептина в пределах 3,7-11,1 нг/мл.

\section{Анализ в подгруппах}

Распределение женщин на группы и подгруппы в зависимости от ИМТ и характера жироотложения представлено на рис. 1.
Этическая экспертиза

Исследование проводилось в соответствии с ГОСТ Р ИСО 14155-2014 на основании заключения локального этического комитета ФГБОУ ВО «Тюменский ГМУ» Минздрава России №69 от 16 июня 2016 г.

\section{Статистический анализ}

Приниипы расчета размера выборки.

Объем выборки предварительно не рассчитывался.

\section{Memodы сmamuстического анализа данных}

Статистическую обработку полученных данных проводили с помощью программы SPSS Statistica 17.0 (США). Тестирование параметров распределения осуществляли с использованием критерия Колмогорова-Смирнова. Количественные переменные представлены в виде средне-

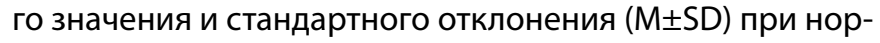
мальном распределении и в виде медианы и значений 25-75 перцентиля - Me (LQ-UQ) - при распределении, отличном от нормального. Различия между выборками устанавливались путем проверок нулевых статистических гипотез с использованием непараметрических тестов Манна-Уитни (U-test), Краскела-Уоллиса (K-W-test). Сравнительный анализ двух зависимых групп проведен с использованием критерия Уилкоксона. Для измерения выраженности связи между двумя переменными использовали корреляцию по Спирмену. Уровень значимости считался достоверным при $\mathrm{p} \leq 0,05$.

\section{РЕЗУЛЬТАТЬ}

Объекты (участники) исследования

Характеристика исходных антропометрических показателей, массы и толщины жировой ткани беременных исследуемых групп представлена в таблице 1.

\section{Основные результаты исследования}

В ходе проведенного исследования установлено, что у беременных с нормальной массой тела в I триместре уровень сывороточного лептина находился в пределах нормативных показателей, в то же время был выше по сравнению с небеременными.

Сравнительный анализ концентрации лептина в исследуемых группах продемонстрировал более высокие

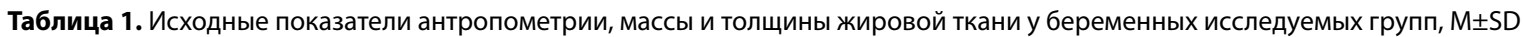

\begin{tabular}{|c|c|c|c|c|c|}
\hline \multicolumn{2}{|c|}{ Показатель } & $\begin{array}{l}\text { Нормальная масса тела } \\
\mathrm{n}=86\end{array}$ & $\begin{array}{c}\text { Избыточная масса тела } \\
\text { n=71 }\end{array}$ & $\begin{array}{c}\text { Ожирение } \\
n=54\end{array}$ & $\begin{array}{c}\text { K-W-test } \\
\text { p-value }\end{array}$ \\
\hline \multicolumn{2}{|c|}{ ИМТ, кг/м² } & $22,3 \pm 1,3$ & $28,5 \pm 1,6$ & $33,9 \pm 1,9$ & $\mathrm{p}<0,0001$ \\
\hline \multicolumn{2}{|c|}{ ОТ/OБ } & $0,84 \pm 0,08$ & $0,82 \pm 0,04$ & $1,09 \pm 0,12$ & $p<0,05$ \\
\hline \multicolumn{2}{|l|}{ ЖМ, кг } & $18,2 \pm 1,5$ & $33,2 \pm 2,6$ & $48,1 \pm 1,4$ & $\mathrm{p}<0,0001$ \\
\hline \multicolumn{2}{|l|}{$\%$ ЖM } & $27,5 \pm 2,2$ & $42,8 \pm 2,2$ & $50,2 \pm 2,1$ & $\mathrm{p}<0,0001$ \\
\hline \multicolumn{2}{|c|}{ Толщина ПКЖ, мм } & $12,7 \pm 2,4$ & $18,7 \pm 3,6$ & $27,7 \pm 3,3$ & $p<0,0001$ \\
\hline Толщина & ППЖ, мм & $11,8 \pm 2,1$ & $15,1 \pm 3,9$ & $24,6 \pm 2,9$ & $\mathrm{p}<0,0001$ \\
\hline ВЖ, мм & ВБЖ, мм & $32,14 \pm 3,12$ & $34,53 \pm 2,91$ & $42,81 \pm 2,76$ & $\mathrm{p}<0,0001$ \\
\hline ИЖБС & & $1,0 \pm 0,2$ & $0,81 \pm 0,2$ & $0,88 \pm 0,12$ & $p=0,0001$ \\
\hline
\end{tabular}

Примечание: анализ с использованием критерия Краскела-Уоллиса (K-W-test). 
Таблица 2. Концентрация лептина у беременных в зависимости от индекса массы тела и срока гестации, Me (LQ-UQ)

\begin{tabular}{|c|c|c|c|c|}
\hline Показатель & $\begin{array}{l}\text { Нормальная масса тела } \\
\mathrm{n}=86\end{array}$ & $\begin{array}{c}\text { Избыточная масса тела } \\
\qquad \mathrm{n}=71\end{array}$ & $\begin{array}{c}\text { Ожирение } \\
n=54\end{array}$ & $\begin{array}{c}\text { K-W-test } \\
\text { p-value }\end{array}$ \\
\hline \multicolumn{5}{|c|}{ I триместр } \\
\hline Лептин, нг/мл & $8,5(4,9-10,0)$ & $21,0(16,8-24,6)$ & $49,6(44,25-53,05)$ & $\mathrm{p} \leq 0,0001$ \\
\hline \multicolumn{5}{|c|}{ II триместр } \\
\hline Лептин, нг/мл & $11,35(8,45-13,65)^{*}$ & $27,4(19,2-34,9)$ & $56,0(46,9-59,7)^{*}$ & $p \leq 0,0001$ \\
\hline \multicolumn{5}{|c|}{ III триместр } \\
\hline Лептин, нг/мл & $29,9(25,9-34)^{* *}$ & $42,0(38,8-46,0)^{* *}$ & $58,0(52,6-62,3)$ & $p \leq 0,0001$ \\
\hline
\end{tabular}

Примечание: анализ с использованием критерия Краскела-Уоллиса (K-W-test); * $\mathrm{p}_{1-1} \leq 0,05$ достоверность различий по сравнению с исходными данными; ** $p_{\|-1 I} \leq 0,05$ - по сравнению с данными II триместра (критерий Уилкоксона).

показатели у женщин с избыточной массой тела и ожирением на протяжении всей беременности (табл. 2).

С увеличением гестационного срока наблюдается рост концентрации лептина среди беременных всех групп (см. табл. 2). В то же время наиболее выраженное увеличение концентрации лептина на протяжении всей беременности наблюдалось в группе женщин с нормальным предгестационным ИМТ ( $p_{1-11}<0,01$ и $\left.\mathrm{p}_{\mathrm{II-III}}<0,001\right)$.

У беременных с избыточной массой тела статистически значимое увеличение уровня лептина произошло только в III триместре $\left(p_{\|-I I I}<0,05\right)$. В группе с ожирением концентрация лептина во II триместре достоверно превышала исходный показатель $\left(p_{1-1 \mid}<0,05\right)$ и не менялась до конца III триместра (см. табл. 2).

У женщин с предгестационным ИМТ 18-24,99 кг/м² В III триместре беременности концентрация лептина в 3,3 раза превышала аналогичный показатель I триместра. В то же время концентрация лептина увеличилась в 2 раза у женщин с избыточной массой тела и в 1,2 раза при ожирении.

В ходе корреляционного анализа выявлено наличие тесных взаимосвязей между уровнем лептина и антропометрическими данными, массой и характером распределения жировой ткани. Установлено, что в I триместре концентрация сывороточного лептина ассоциирована с ИМТ $(r=0,802 ; p=0,000)$ и жировой массой $(r=0,803$;

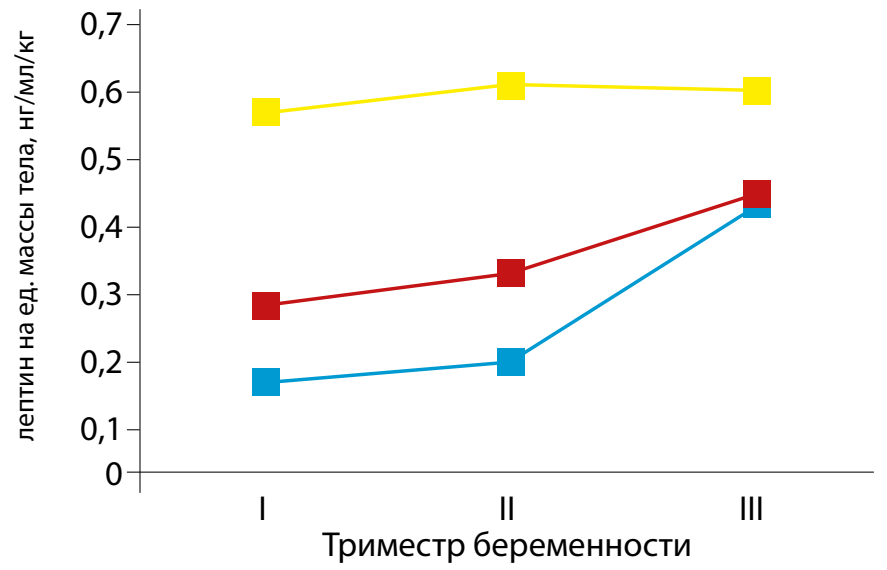

Нормальная масса тела Ожирение

Рис. 2. Динамика прироста концентрации лептина на единицу массы тела у беременных с нормальной, избыточной массой тела и ожирением. p=0,000). С увеличением срока беременности взаимосвязь концентрации лептина с предгестационным ИМТ ослабевает, однако остается статистически значимой во II $(r=0,641 ; p \leq 0,001)$ и III триместрах $(r=0,50 ; p \leq 0,001)$.

Анализ взаимосвязи уровня лептина с характером жироотложения (по результатам УЗИ) продемонстрировал положительную корреляцию с увеличением толщины как подкожного, так и висцерального жира. В I триместре у беременных всех групп концентрация лептина в большей степени ассоциирована с толщиной подкожного жира ( $r=0,917 ; p=0,000)$, чем висцерального ( $r=0,568$; $\mathrm{p}=0,0000)$. С увеличением гестационного срока в общей когорте беременных сохраняется статистически значимая корреляция уровня лептина с толщиной подкожного и висцерального жира, однако усиливается взаимосвязь с толщиной жировой ткани висцеральной локализации $(r=0,846 ; p=0,00012)$.

В ходе сравнительного анализа динамики прироста концентрации лептина в пересчете на 1 кг массы тела и жировой массы установлены различия, определяющиеся исходными антропометрическими данными (рис. 2 и 3).

Дополнительные результаты исследования

В ходе сравнительного анализа концентрации лептина в зависимости от преимущественного типа жироотло-

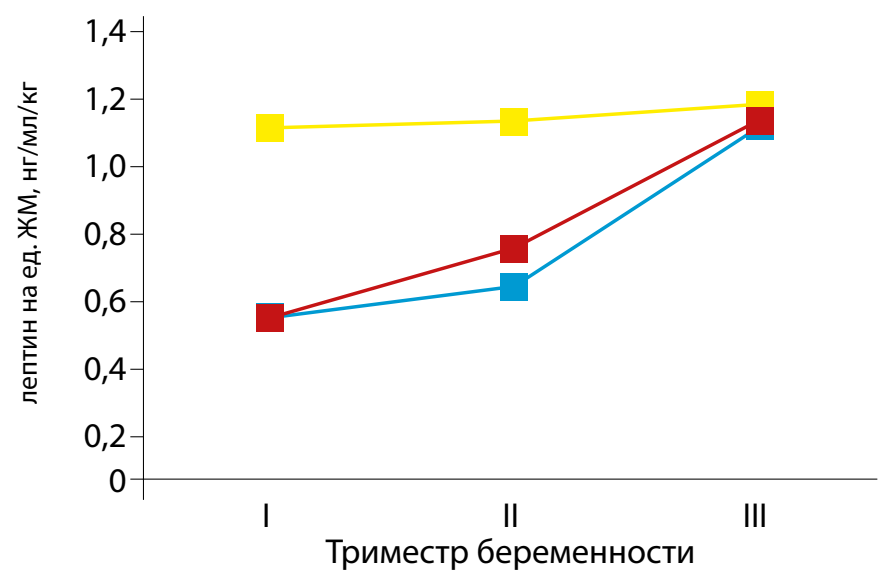

Нормальная масса тела Избыточная масса тела Ожирение

Рис. 3. Динамика прироста концентрации лептина на единицу жировой массы у беременных с нормальной, избыточной массой тела и ожирением. 
Таблица 3. Динамика показателей концентрации лептина у беременных с нормальной массой тела в зависимости от типа преимущественного жироотложения, Me (LQ-UQ)

\begin{tabular}{|c|c|c|c|}
\hline Показатель & Висцеральный тип n=46 & Подкожный тип n=40 & U-test p-value \\
\hline \multicolumn{4}{|c|}{ I триместр } \\
\hline Лептин, нг/мл & $7,9(4,6-9,8)$ & $8,8(8,5-10,2)$ & $p=0,245$ \\
\hline \multicolumn{4}{|c|}{ II триместр } \\
\hline Лептин, нг/мл & $11,9(9,3-14,0)$ & $10,6(8,2-13,0)$ & $p=0,241$ \\
\hline \multicolumn{4}{|c|}{ III триместр } \\
\hline Лептин, нг/мл & $32,6(26,4-36,0)$ & $28,2(24,5-31,0)$ & $p=0,021$ \\
\hline
\end{tabular}

Приложение: анализ и использование критерия Mann-Whitney (U-test).

Таблица 4. Динамика показателей концентрации лептина у беременных с избыточной массой в зависимости от типа преимущественного жироотложения, Me (LQ-UQ)

\begin{tabular}{|c|c|c|c|}
\hline Показатель & Висцеральный тип n=30 & Подкожный тип n=41 & U-test p-value \\
\hline \multicolumn{4}{|c|}{ I триместр } \\
\hline Лептин, нг/мл & $16,5(14,3-23,0)$ & $21,4(16,4-24,6)$ & $p=0,027$ \\
\hline \multicolumn{4}{|c|}{ II триместр } \\
\hline Лептин, нг/мл & $25,7(19,3-34,5)$ & $28,0(18,0-36,0)$ & $p=0,703$ \\
\hline \multicolumn{4}{|c|}{ III триместр } \\
\hline Лептин, нг/мл & $40,0(34,5-46,0)$ & $44,2(41,5-48,6)$ & $p=0,099$ \\
\hline
\end{tabular}

Приложение: анализ и использование критерия Mann-Whitney (U-test).

Таблица 5. Динамика показателей концентрации лептина у беременных с ожирением в зависимости от типа преимущественного жироотложения, Me (LQ-UQ)

\begin{tabular}{lcccc}
\hline \multicolumn{1}{c}{ Показатель } & Висцеральный тип $\mathbf{n = 1 9}$ & Подкожный тип $\mathbf{n = 3 5}$ & U-test p-value \\
\hline \multirow{2}{*}{ Лептин, нг/мл } & І триместр & & \\
& $48,90(42,85-53,65)$ & & $49,6(44,25-53,8)$ & $\mathrm{p}=0,265$ \\
Лептин, нг/мл & II триместр & & \\
& $56,45(48,45-56,45)$ & $55,15(46,9-59,60)$ & $\mathrm{p}=0,728$ \\
Лептин, нг/мл & III триместр & & $\mathrm{p}=0,757$ \\
\hline
\end{tabular}

Приложение: анализ и использование критерия Mann-Whitney (U-test).

жения в группе с нормальной массой тела в I и II триместре достоверных различий не обнаружено (табл. 3).

В III триместре зарегистрированы достоверно более высокие уровни лептина в группе с преимущественно висцеральным типом жироотложения по сравнению с аналогичным показателем в группе с подкожным характером распределения жировой ткани (табл. 3).

У женщин с избыточной массой тела концентрация лептина при подкожном характере жироотложения достоверно выше только в I триместре беременности (табл. 4).

У женщин с ожирением концентрация лептина на протяжении всего гестационного периода не зависела от характера жироотложения (табл. 5).

Нежелательные явления

В ходе исследования не было отмечено нежелательных явлений, которые могли бы повлиять на его результаты.

\section{ОБСУЖДЕНИЕ}

Резюме основного результата исследования

Таким образом, в результате проведенного исследования было установлено, что уровень сывороточного лептина нарастает пропорционально предгестационному ИМТ у всех беременных начиная с I триместра и продолжает увеличиваться с ростом гестационного срока независимо от характера жироотложения. К концу беременности наиболее выраженное увеличение концентрации лептина по отношению к предгестационному уровню зарегистрировано в группе женщин с нормальной массой тела.

Обсуждение основного результата исследования

Результаты проведенного исследования свидетельствуют, что уровень сывороточного лептина в I триместре повышается еще до увеличения жировой массы и веса женщины. Данный факт свидетельствует, что в период беременности не только жировая ткань, но и дру- 
гие факторы влияют на уровень лептина, что является подтверждением ранее доказанной его роли в процессе инвазии трофобласта, стимуляции ангиогенеза, регуляции плацентарного роста и переноса питательных веществ к плоду [22-24].

Более высокие уровни лептина в I триместре у беременных с избыточной массой и ожирением объясняются большим содержанием жировой массы и преобладанием пациенток с преимущественно подкожным характером жироотложения. Подобная тенденция наблюдается у небеременных женщин $[25,26]$ и объясняется более выраженной экспрессией лептина в жировой ткани подкожной локализации. Кроме того, возможным объяснением этих различий служит развитие лептинорезистентности у беременных, имеющих избыточную массу и ожирение. Подтверждением этому могут служить результаты исследования Е.Н. Смирновой (2017), в котором показано, что лица с нормальной массой тела имеют более высокий уровень свободных рецепторов лептина по сравнению с пациентами с простым ожирением и метаболическим синдромом, что закономерно проявляется низкими значениями индекса свободного лептина [27].

С увеличением гестационного срока рост концентрации лептина наблюдается во всех группах, однако наиболее заметно этот рост был выражен в группе с нормальным предгестационным ИМТ. Данный факт свидетельствует о различиях в метаболической адаптации к беременности, которые определяются исходным статусом женщины. Беременные с нормальной массой тела имели большую величину гестационной прибавки веса и жировой массы относительно исходных показателей, чем женщины с избыточной массой тела и ожирением, что дает основания полагать, что увеличение массы жировой ткани может оказывать существенное влияние на синтез лептина у данной категории женщин [28]. Положительная корреляция уровня сывороточного лептина с толщиной висцерального жира во II и III триместре свидетельствует о свойственном периоду беременности перераспределению жировых отложений с преимущественной локализацией в висцеральной области.

\section{ЗАКЛЮЧЕНИЕ}

Несмотря на большое количество проводимых исследований, многие вопросы, касающиеся связи ожирения с воспалением и дисбалансом адипоцитокинов, до сих пор остаются до конца не изученными.

Полученные результаты демонстрируют различия метаболических особенностей течения беременности у женщин с нормальной, избыточной массой тела и ожирением. Учитывая важную роль лептина в регуляции энергетического обмена, процесса имплантации и функционирования фетоплацентарного комплекса, изучение особенностей его секреции в различные сроки гестации должно внести существенный вклад в понимание патогенеза ассоциированных с ожирением акушерских осложнений.

У беременных с избыточной массой тела и ожирением гиперлептинемия начиная с I триместра объясняется избыточным содержанием жировой ткани, преимущественно подкожной локализации. Наибольшая величина гестационной прибавки массы тела и жировой массы в группе женщин с нормальным исходным весом сопровождается увеличением уровня лептина на единицу массы тела и жировой массы. Эти данные свидетельствуют, что контроль и ограничение чрезмерной прибавки веса в период беременности может являться мерой профилактики избыточной секреции лептина и связанных с этим гестационных осложнений.

\section{ДОПОЛНИТЕЛЬНАЯ ИНФОРМАЦИЯ.}

Источник финансирования. Исследование не имело финансовой поддержки.

Конфликт интересов. Авторы декларируют отсутствие явных и потенциальных конфликтов интересов, связанных с публикацией настоящей статьи.

\section{СПИСОК ЛИТЕРАТУРЫ | REFERENCES}

1. Behnes M, Brueckmann M, Lang S, et al. Alterations of leptin in the course of inflammation and severe sepsis. BMC Infect Dis. 2012;12(1):217. doi: 10.1186/1471-2334-12-217

2. Pérez-Pérez A, Sánchez-Jiménez F, Maymó J, et al. Role of leptin in female reproduction. Clin Chem Lab Med. 2015;53(1):15-28. doi: 10.1515/cclm-2014-0387

3. Петунина Н.А., Кузина И.А. Роль гормонов жировой ткани в развитии осложнений беременности у женщин с ожирением // Ожирение и метаболизм. - 2013. - T.10. - №1 - C.3-8. [Petunina NA, Kuzina IA. The role of hormones of adipose tissue in the development pregnancy complications in obese women. Ožirenie i metabolizm. 2013;10(1):3-8. (In Russ.)] doi: 10.14341/2071-8713-2013-1

4. Суплотова Л.А., Сметанина С.А., Плотников Н.В., Мурычева К.А. Клинико-метаболические и молекулярно-генетические ассоциации у женщин репродуктивного возраста при инсулинорезистентности, ожирении и метаболическом синдроме // Медицинская наука и образование Урала. - 2013. - Т.14. - №2. C.84-87. [Suplotova LA, Smetanina SA, Plotnikov NV, Muricheva KA. Associations of clinical, metabolic and molecular genetic markers of insulin resistance for womens of reproductive age with obesity and metabolic syndrome. Medicinskâ̂ nauka i obrazovanie Urala. 2013;14(2):84-87. (InRuss.)]
5. Masuzaki H, Ogawa Y, Sagawa N, et al. Nonadipose tissue production of leptin: Leptin as a novel placenta-derived hormone in humans. Nat Med. 1997;3(9):1029-1033. doi: 10.1038/nm0997-1029

6. Pérez-Pérez A, Toro A, Vilariño-García T, et al. Leptin action in normal and pathological pregnancies. J Cell Mol Med. 2017;22(2):716-727. doi: $10.1111 / \mathrm{jcmm} .13369$

7. Горбатенко Н.В., Беженарь В.Ф., Фишман М.Б. Влияние ожирения на развитие нарушения репродуктивной функции у женщин (аналитический обзор литературы) // Ожирение и метаболизм. 2017. - T.14. - №.1 - C.3-8. [Gorbatenko NV, Bezhenar VF, Fishman MB. Obesity and reproductive health of women. Ožirenie i metabolism. 2017;14(1):3-8. (In Russ.)] doi: 10.14341/OMET201713-8

8. Чабанова Н.Б., Матаев С.И., Василькова Т.Н., Трошина И.А. Метаболические нарушения при адипоцитокиновом дисбалансе и гестационные осложнения // Ожирение и метаболизм. - 2017. - Т.14. - №.1 - С.9-16. [Chabanova NB, Mataev SI, Vasilkova TN, Troshina IA. Metabolic disorders in adipocytokine imbalance and gestational complications. Ožireniei metabolism. 2017;14(1):9-16. (In Russ.)] doi: 10.14341/OMET201719-16

9. Taylor BD, Ness RB, Olsen J, et al. Serum Leptin Measured in Early Pregnancy Is Higher in Women With Preeclampsia Compared With Normotensive Pregnant Women. Hypertension. 2015;65(3):594-599. doi: 10.1161/HYPERTENSIONAHA.114.03979 
10. Pérez-Pérez A, Guadix P, Maymó J, et al. Insulin and Leptin Signaling in Placenta from Gestational Diabetic Subjects. Horm Metab Res. 2015:48(01):62-69. doi: 10.1055/s-0035-1559722

11. Pérez-Pérez A, Maymó J, Gambino Y, et al. Activated Translation Signaling in Placenta from Pregnant Women with Gestational Diabetes Mellitus: Possible Role of Leptin. Horm Metab Res. 2013;45(06):436442. doi: 10.1055/s-0032-1333276

12. Garrido-Gimenez C, Alijotas-Reig J. Recurrent miscarriage: causes, evaluation and management. Postgrad Med J. 2015;91(1073):151-162. doi: 10.1136/postgradmedj-2014-132672

13. Zidan HE, Rezk NA, Alnemr AAA, Moniem MIA. Interleukin-17 and leptin genes polymorphisms and their levels in relation to recurrent pregnancy loss in Egyptian females. Immunogenetics. 2015;67(1112):665-673. doi: 10.1007/s00251-015-0876-8

14. Salem H, Rosenfeld T, Altarescu G, Grisaru-Granovsky S, Birk R. Maternal and neonatal leptin and leptin receptor polymorphisms associated with preterm birth. Gene. 2016;591(1):209-213. doi: 10.1016/j. gene.2016.07.014

15. Lausten-Thomsen U, Christiansen M, Hedley PL, Holm J-C, Schmiegelow K. Adipokines in umbilical cord blood from children born large for gestational age. J Pediatr Endocrinol Metab. 2016;29(1):33-37. doi: 10.1515/jpem-2014-0502

16. Briana DD, Malamitsi-Puchner A. Intrauterine growth restriction and adult disease: the role of adipocytokines. Eur J Endocrinol. 2009;160(3):337-347. doi: 10.1530/EJE-08-0621

17. Щербаков В.И., Поздняков И.М., Ширинская А.В., Волков М.В. Изучение уровня энергетического регулятора лептина и хемокина cхcl8 в условиях угрозы преждевременных родов и при преэклампсии // Сибирский научный медицинский журнал. 2015. - Т.35. - №6. C.52-55. [Shcherbakov VI, Pozdnyakov IM, Shirinskaya AV, Volkov MV. Studying of energy balance regulators - leptin and CXCL8 chemokin levels under condition of premature birth threatening and at preeclampsia. Sibirskij naučnyj medicinskij žurnal. 2017;35(6):52-55. (In Russ.)]

18. Д.В. Николаев, А.В. Смирнов, И.Г. Бобринская, С.Г. Руднев. Биоимпедансный анализ состава тела человека. - М: Наука, 2009. [Nikolaev DV, Smirnov AV, Bobrinskaya IG, Rudnev S.G. Bioelectric impedance analysis of human body composition. Moscow: Nauka; 2009. (In Russ.)]
19. Tayama K, Inukai T, Shimomura Y. Preperitoneal fat deposition estimated by ultrasonography in patients with non-insulin-dependent diabetes mellitus. Diabetes Res Clin Pract. 1999:43(1):49-58. doi: 10.1016/S0168-8227(98)00118-1

20. Armellini F, Zamboni M, Rigo L, et al. The contribution of sonography to the measurement of intra-abdominal fat. J Clin Ultrasound. 1990;18(7):563-567. doi: 10.1002/jcu.1870180707

21. Suzuki R, Watanabe $S$, Hirai Y, et al. Abdominal wall fat index, estimated by ultrasonography, for assessment of the ratio of visceral fat to subcutaneous fat in the abdomen. Am J Med. 1993;95(3):309-314 doi: 10.1016/0002-9343(93)90284-V

22. Hauguel-de Mouzon S, Lepercq J, Catalano P. The known and unknown of leptin in pregnancy. Am J Obstet Gynecol. 2006;194(6):1537-1545. doi: 10.1016/j.ajog.2005.06.064

23. Naylor C, Petri WA. Leptin Regulation of Immune Responses. Trends Mol Med. 2016;22(2):88-98. doi: 10.1016/j.molmed.2015.12.001

24. Pérez-Pérez A, Maymó J, Gambino Y, et al. Leptin Stimulates Protein Synthesis-Activating Translation Machinery in Human Trophoblastic Cells1. Biol Reprod. 2009. doi: 10.1095/biolreprod.109.076513

25. Панков Ю.А. Лептин и его медиаторы в регуляции жирового обмена // Ожирение и метаболизм. - 2010. - Т.7. - №2. - С.3-9. [Pankov YA. Leptin and its mediators in the regulation of lipid metabolism. Ožirenie i metabolism. 2010;7(2):3-9. (In Russ.)] doi: 10.14341/2071-8713-5202

26. Van Harmelen V, Reynisdottir S, Eriksson P, et al. Leptin secretion from subcutaneous and visceral adipose tissue in women. Diabetes. 1998;47(6):913-917. doi: 10.2337/diabetes.47.6.913

27. Смирнова Е.Н., Шулькина С.Г. Содержание лептина, растворимых рецепторов лептина и индекса свободного лептина у больных с метаболическим синдромом // Ожирение и метаболизм. - 2017. - T.14. - №.1 - C.30-34. [Smirnova EN, Shulkina SG. Leptin, soluble leptin receptor and the free leptin index in patients with metabolic syndrome. Ožirenie i metabolism. 2017;14(1):30-34. (In Russ.)] doi: 10.14341/OMET2017130-34

28. Lönnqvist F, Nordfors L, Jansson M, Thörne A, Schalling M, Arner P. Leptin secretion from adipose tissue in women. Relationship to plasma levels and gene expression. J Clin Invest. 1997;99(10):2398-2404. doi: $10.1172 / \mathrm{JCl} 119422$

\section{ИНФОРМАЦИЯ ОБ АВТОРАХ [AUTHORS INFO]}

*Чабанова Наталья Борисовна, к.м.н. [Natalya B. Chabanova, MD, PhD]; адрес: Россия, 625023, г. Тюмень, ул. Одесская, д. 54 [address: 54 Odesskaya street, 625023 Tyumen, Russia]; ORCID: http://orcid.org/0000-0003-3173-021X; eLibrary SPIN: 6627-6605; e-mail: Natalya.Chabanova@gmail.com

Василькова Татьяна Николаевна, д.м.н., професcop [Tatyana N. Vasilkova, MD, ScD, professor]; eLibrary SPIN: 34104460; e-mail: vasilkovatn@rambler.ru

Полякова Валентина Анатольевна, д.м.н., професcop [Valentina A. Polyakova, MD, ScD, professor]; eLibrary SPIN: 13113912; e-mail: polycova_gyn@mail.ru

Матаев Сергей Иванович, д.м.н., професcop [Sergei I. Mataev, MD, ScD, professor]; e-mail: mataevci@rambler.ru

\section{ЦИТИРОВАТЬ:}

Чабанова Н.Б., Василькова Т.Н., Полякова В.А., Матаев С.И. Влияние массы и характера распределения жировой ткани на содержание лептина у беременных в различные сроки гестации // Ожирение и метаболизм. — 2019. — Т.16. — №1. — C. 55-61. doi: 10.14341/omet9505

\section{TO CITE THIS ARTICLE:}

Chabanova NB, Vasilkova TN, Polyakova VA, Mataev SI. Influence of mass and distribution of adipose tissue on the content of leptin in pregnant women at different periods gestations. Obesity and metabolism. 2019;16(1):55-61. doi: 10.14341/ omet9505 